\title{
MIĘDZY WSCHODEM A ZACHODEM. INWENTARZ KRZEMIENNY Z OSADY LUDNOŚCI KULTURY CERAMIKI WSTĘGOWEJ RYTEJ NA STANOWISKU PODLESIE 6, WOJ. ŚWIĘTOKRZYSKIE
}

\author{
BETWEEN EAST AND WEST. FLINT ASSEMBBLAGE \\ OF THE LINEAR POTTERY CULTURE SOCIETIES FROM SITE 6 \\ IN PODLESIE, ŚWIETTOKRZYSKIE VOIVODESHIP
}

\author{
Michat Przézdziecki \\ https://orcid.org/0000-0002-8605-3941 \\ Wydział Archeologii, Uniwersytet Warszawski \\ ul. Krakowskie Przedmieście 26/28, 00-927 Warszawa \\ m.przezdziecki@uw.edu.pl \\ Michat Szubski \\ https://orcid.org/0000-0003-0873-8686 \\ Instytut Archeologii, Uniwersytet Kardynała Stefana Wyszyńskiego w Warszawie \\ ul. Wóycickiego 1/3, bud. 23, 01-938 Warszawa \\ michal.szubski@gmail.com

\section{Artur Grabarek} \\ https://orcid.org/0000-0003-2670-4519 \\ Wydział Archeologii, Uniwersytet Warszawski \\ ul. Krakowskie Przedmieście 26/28, 00-927 Warszawa \\ a.grabarek@uw.edu.pl
}

\begin{abstract}
Paper presents results of analysis of the assemblage of flint artefacts from the settlement of Linear Pottery culture (LBK) at the site no. 6 in Podlesie, Świętokrzyskie voivodeship. Importance of the site is primarily by its location: on the border of two geographical regions, two geological conditions, two settlement eccentrics of the LBK and two provinces of lithic raw materials. Within the flint assemblage we can distinguish two main classes of lithical artefacts: an internally cohesive collection of 104 obsidian products and a collection of 2069 artefacts made of at least five different types of flint. In the group of
\end{abstract}


siliceous rocks, the most numerous is the Jurassic flint from Cracow area $-53 \%$. Second place in the inventory is occupied by the Światchowski flint, which share reaches the level of $19 \%$. Only slightly smaller are amounts of chocolate flint $-15 \%$.

KEY WORDS: Neolithic, LBK communities, Podlesie 6, lithic analysis, Jurassic Flint, raw materials

Celem artykułu jest prezentacja wyników analizy inwentarza zabytków krzemiennych z osady społeczności kultury ceramiki wstęgowej rytej (dalej KCWR) na stanowisku nr 6 w Podlesiu, pow. staszowski, woj. świętokrzyskie. Obejmują one charakterystykę zbioru pod względem surowcowym, stylistycznym, technologicznym oraz typologicznym, przy czym szczególną uwagę poświęcono pierwszemu z wymienionych aspektów, tj. strukturze surowcowej, która w przypadku omawianego stanowiska wydaje się wyjątkowa. Obok kwestii podstawowych, takich jak identyfikacja poszczególnych odmian skał krzemionkowych, określenie ich proweniencji oraz kontekstu występowania w przestrzeni stanowiska, podjęto także próbę ustalenia ich atrybucji chronologicznej, polegającej na powiązaniu wyróżnionych $\mathrm{w}$ inwentarzu rodzajów krzemieni z konkretnymi fazami osadniczymi, zdefiniowanymi wcześniej na podstawie studium materiałów ceramicznych i danych stratygraficznych.

W przekonaniu autorów określony w ten sposób zakres analiz powinien umożliwić sformułowanie wstępnych wniosków na temat sposobów pozyskiwania, obróbki i wykorzystania surowców krzemiennych przez mieszkańców osady.

\section{STANOWISKO NR 6 W PODLESIU}

Podlesie to niewielka wieś położona w gminie Oleśnica, w środkowej części Niecki Połanieckiej, będącej jednym z mezoregionów Wyżyny Małopolskiej (Kondracki, 2002, s. 269-270). Obszar badań, oznaczony jako stanowisko nr 6, obejmuje fragment południowego stoku oraz krawędź doliny rzeki Wschodniej, prawego dopływu Czarnej (ryc. 1). Zlokalizowany jest na podłożu zbudowanym z iłów krakowieckich, przykrytych reziduum glin plejstoceńskich zlodowaceń południowoi środkowopolskich oraz z osadów deluwialnych. Na podstawie wyników prospekcji powierzchniowej, badań geofizycznych oraz odwiertów sondażowych przybliżoną wielkość osady należy szacować na ok. 2 ha.

Stanowisko zostało odkryte przypadkowo w 2009 roku przez jednego z mieszkańców wsi, który podczas prac polowych zwrócił uwagę na liczne, zalegające na powierzchni fragmenty ceramiki oraz przedmioty krzemienne. Od 2014 roku w miejscu tym prowadzone są prace wykopaliskowe, którymi kieruje Artur Grabarek z Instytutu Archeologii Uniwersytetu Warszawskiego. W trakcie sześciu sezonów badawczych rozpoznano powierzchnię 8,3 ara, rejestrując przy tym blisko 40 obiektów. Szczególną uwagę wzbudza długi dom oraz liczne, związane z nim dołki posłupowe. Ponadto odsłonięto jamy gospodarcze. $\mathrm{Z}$ ich wypełnisk, ale także z warstwy kulturowej pozy- 
skano łącznie ponad 14,5 tys. zabytków ruchomych, reprezentujących pięć różnych kategorii surowcowych: ceramikę (naczyniową i nienaczyniową), kamień, krzemień, obsydian oraz kości zwierzęce.

Aktualny stan rozpoznania stanowiska umożliwia wyróżnienie dwóch stref (zachodniej i wschodniej) charakteryzujących się wyraźnie wyższym stopniem nasycenia artefaktami. Szczególnie duże nagromadzenie materiału zabytkowego, w tym ceramiki, krzemieni oraz zwierzęcych szczątków kostnych, pozwala przyjąć założenie, że na południowy zachód od długiego domu, w naturalnym nieckowatym obniżeniu terenu znajdowała się wydzielona strefa gospodarcza/śmietnikowa.

Z perspektyw dalszych rozważań warto zwrócić uwagę na kilka kwestii związanych z metodyką badań, istotną przy ocenie reprezentatywności bazy źródłowej, a w konsekwencji wiarygodności formułowanych wniosków. Eksplorację prowadzono ręcznie, metodą gracowania. Warstwę kulturową, w zależności od jej charakteru, a przede wszystkim stopnia nasycenia substancją zabytkową, usuwano plastycznie, poziomami mechanicznymi o miąższości $1-3 \mathrm{~cm}$. Wszystkie zabytki, z wyjątkiem fragmentów ceramiki, lokalizowano trójwymiarowo z dokładnością do $0,5 \mathrm{~cm}$. Dodatkową procedurą dla obiektów było flotowanie i przesiewanie wybranych części wypełnisk. Zasadność przyjętej metodyki badań znajduje bezpośrednie odzwierciedlenie w liczbie zarejestrowanych zabytków, ale przede wszystkim w ich rozmiarach (wysoka frekwencja bardzo drobnych znalezisk o średnicy poniżej $0,5 \mathrm{~cm}$ ) oraz szczegółowo zadokumentowanym kontekście występowania. Uwagi te są o tyle istotne, że często jako jeden z problemów w procesie analizy i interpretacji inwentarzy krzemiennych KCWR wskazuje się właśnie kwestie metodyczne (sposób pozyskiwania źródeł na etapie badań terenowych). Z taką sytuacją mamy do czynienia m.in. w osadzie w Samborcu, J. Lech (2008, s. 182-184) zwraca uwagę na niemal całkowity brak tam zabytków o małych rozmiarach, łącząc to z przyjętymi procedurami eksploracyjnymi. Na Wyżynie Małopolskiej znanych jest 627 stanowisk KCWR, z czego na zaledwie około 80 prowadzono jakiekolwiek badania. W tej grupie znajdują się zarówno rozległe, kilkudziesięcioarowe osady, wśród których można wyróżnić m.in.: Samobrzec (Kulczycka-Leciejewiczowa, 2008, s. 63), Tominy (Szeliga, Zakościelna, 2007, s. 9-11), Wólka Wojnowska (Matyaszewski, 2017, s. 3), jak również stanowiska kilkuarowe: Bukówka-Zapniów (Hadamik, 2005, s. 31), Iłża-Chwałowski Trakt (Bujakowski, Kmicik, 2005, s. 38), Michałowice (Kruk, 1969, s. 356-357), Szewna ${ }^{1}$, ale także takie, gdzie wystąpiły tylko pojedyncze obiekty KCWR, np.: Zagość Parcelacja (Gromnicki, 1965, s. 171172), Kargów² ${ }^{2}$ Kowala (Krauss, 1970, s. 157-174). Należy również podkreślić, że w większości są to stanowiska wielokulturowe.

Podsumowując stan badań nad KCWR na Wyżnie Małopolskiej, warto też zwrócić uwagę, że dotychczas obejmowały one niemal wyłącznie dwie główne enklawy pierwszą skupioną wokół lessów miechowskich (podkrakowskich) i drugą na obsza-

\footnotetext{
'Sprawozdanie z badań wykopaliskowych w WUOZ w Kielcach.

${ }^{2}$ Informacja ustna S. Wilka.
} 
rze lessów opatowsko-sandomierskich. Trzecim, najsłabiej dotychczas rozpoznanym, choć jak się wydaje równie ważnym regionem związanym z osadnictwem ludności KCWR, jest dorzecze Wschodniej, obejmujące głównie pozalessowy mezoregion Niecki Połanieckiej oraz lessowe partie Garbu Pińczowskiego (ryc. 1). Położona na iłach krakowieckich osada w Podlesiu jest pierwszym badanym wykopaliskowo stanowiskiem w tej strefie. Należy podkreślić również, że jest to stanowisko jednokulturowe, na którym zarejestrowano wyłącznie materiały z fazy nutowej i żeliezowskiej KCWR oraz pojedyncze zabytki związane z kulturą/grupą Tisadob-Kapuśany, a także kulturą bukowogórską z kręgu wschodniolinearnego.

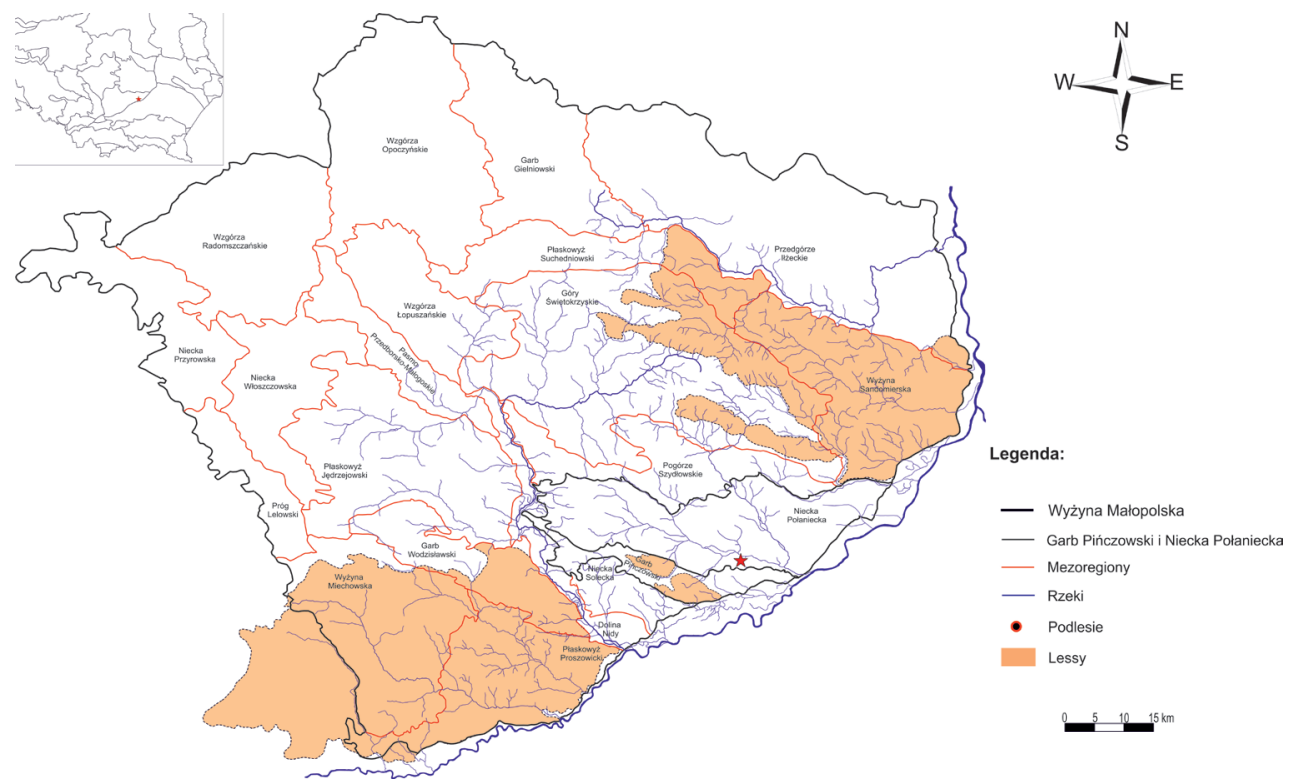

Ryc. 1. Lokalizacja stanowiska 6 w Podlesiu, woj. świętokrzyskie (rys. A. Grabarek)

Fig. 1. Localization of site 6 in Podlesie, świętokrzyskie voievodeship (drawing by A. Grabarek)

Z perspektywy rozważań nad wytwórczością krzemieniarską KCWR wyjątkowość osady w Podlesiu wynika $\mathrm{z}$ jej położenia, między dwiema prowincjami surowcowymi - świętokrzyską, z wychodniami krzemienia czekoladowego i pasiastego, oraz śląsko-krakowską, stanowiącą obszar występowania krzemieni jurajskich „podkrakowskich”. W stosunkowo niewielkim oddaleniu, choć już na prawym brzegu Wisły, znajdują się z kolei złoża - dość licznie reprezentowanego w Podlesiu - krzemienia świeciechowskiego. Dodatkowo na ten skomplikowany obraz świadczący o wielokierunkowych i dalekodystansowych kontaktach mieszkańców osady nakłada się jeszcze obecność licznych wytworów obsydianowych ze złóż południowokarpackich. 


\section{OGÓLNA CHARAKTERYSTYKA BAZY ŹRÓDLOWEJ}

Przedmiotem opracowania są materiały z badań wykopaliskowych prowadzonych w latach 2014-2018. W ramach inwentarza 2173 zabytków litycznych wydzielić możemy dwie główne kategorie surowcowe, tj. grupę 104 wyrobów obsydianowych $(4,8 \%)$ oraz zbiór 2069 artefaktów krzemiennych (95,2\%). Jak zaznaczono na wstępie, w niniejszym opracowaniu skoncentrowano się na omówieniu ostatniej z wymienionych kategorii, tj. zabytkach krzemiennych. Niezwykle interesująca kolekcja przedmiotów z obsydianu została szczegółowo scharakteryzowana w odrębnym artykule (Szeliga, Przeździecki, Grabarek, 2019). Interesująca nas grupa artefaktów stanowi drugą pod względem liczebności kategorię znalezisk ruchomych, odkrytych w ramach dotychczasowych badań. Pochodzą one zarówno z warstw akumulacyjnych, jak i obiektów, przy czym w obu kontekstach rejestrowane były zawsze w towarzystwie innych kategorii źródeł - fragmentów ceramiki, przedmiotów kamiennych lub szczątków kostnych.

\section{Struktura surowcowa}

W grupie zabytków ze skał krzemionkowych najliczniej reprezentowany jest krzemień jurajski podkrakowski (53\%) (ryc. 2), odmiany, którą można identyfikować z typem tzw. olszanickim (Lech, 1980), tj. szklistej, o wyraźnej przezroczystości i brązowej barwie, z niewielkimi białymi intruzjami. Zdecydowanie rzadsze są wytwory wykonane z odmiany woskowej o miodowej barwie (Kaczanowska, Kozłowski, 1976). Surowiec ten charakteryzuje się dobrą łupliwością, co wynika nie tylko z właściwości samej krzemionki, ale także jej ,jednorodności” oraz braku wtrętów, ponadto występuje w postaci regularnych, dość dużych konkrecji. Wysokie walory użytkowe umożliwiające efektywną produkcję długich wiórów sprawiały, że krzemień ten był na dużą skalę wykorzystywany przez społeczności KCWR, które pozyskiwały go metodami górniczymi (Dzieduszycka-Machnikowa, Lech, 1976; Lech, 1981, 1983). „Kopalniane” pochodzenie brył dostarczanych na teren osady w Podlesiu potwierdza występowanie na części zabytków krzemienia jurajskiego podkrakowskiego grubej kory bez śladów erozji.

Kolejne miejsca w omawianym inwentarzu zajmują krzemień świeciechowski, którego udział osiąga 19\%, oraz krzemień czekoladowy, oznaczony w przypadku $15 \%$ wyrobów (Schild, 1971; Budziszewski, 2008). Na podstawie analizy cech makroskopowych (barwy, tekstury, połyskliwości) możliwe jest wydzielenie kilku występujących na stanowisku rodzajów surowca czekoladowego. Niemniej najbardziej charakterystyczna, a jednocześnie dominująca pod względem ilościowym jest odmiana przypominająca typ znany z Tomaszowa (Schild i in., 1985). Na przedostatniej pozycji znalazł się kredowy narzutowiec, tj. krzemień narzutowy bałtycki, którego udział w inwentarzu wynosi ok. 5\%. Listę zaś zamykają 2 artefakty z krzemienia pasiastego. Wśród znalezisk ze skał krzemionkowych wystąpiła także, stanowiąca łącznie ok. 6\%, grupa zabytków nieokreślonych, tj. przekształconych termicznie (przepalonych) w stopniu uniemożliwiającym ich precyzyjną identyfikacje surowcową (ryc. 2). 


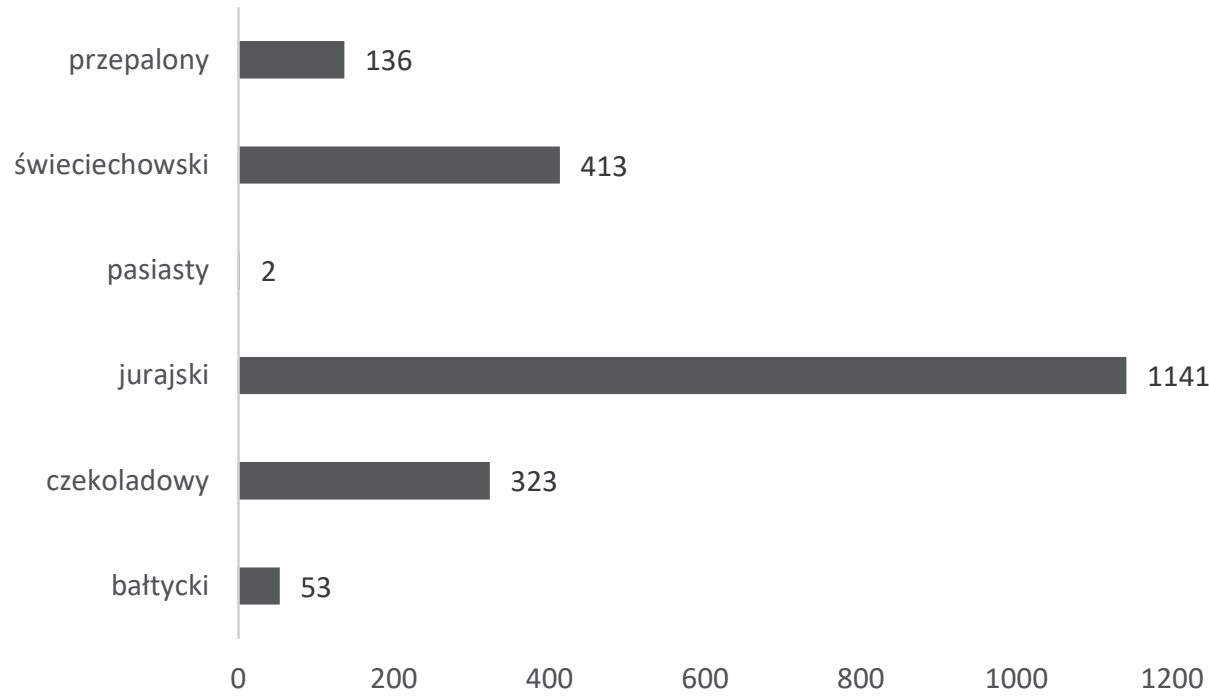

Ryc. 2. Frekwencja poszczególnych odmian surowców krzemiennych (rys. M. Przeździecki)

Fig. 2. Examples of flint artefacts (drawing by M. Przeździecki)

\section{Charakterystyka technologiczna i stylistyczna}

Rozpoczynając opis grupy zabytków krzemiennych, należy przede wszystkim podkreślić ich jednolity, wyraźnie zestandaryzowany charakter, czytelny zarówno na poziomie cech morfometrycznych, technologicznych, jak i ogólnej struktury typologicznej (por. Balcer, 1983, s. 56; Kaczanowska, 1985, s. 40). Najważniejszym atrybutem kształtującym zasadniczy obraz analizowanego zbioru są regularne, mediolityczne lub submakrolityczne wióry jednopiętowe o równoległym układzie grani międzynegatywowych i krawędzi bocznych, zbiegających się gwałtownie w części wierzchołkowej. Nadaje im to charakterystyczny podprostokątny lub podstożkowy pokrój. Do niewątpliwie dystynktywnych cech należy występowanie fasetowanych, dwuściennych piętek z wyraźnie wyniesionym punktem przyłożenia siły (ostrogą), prosty profil z delikatnym (krótkoodcinkowym) wychyleniem w partii proksymalnej i podwinięciem w partii dystalnej, trapezowaty przekrój poprzeczny, a także wyraźny, choć stosunkowo słabo wysklepiony sęczek (por. Wąs, 2011). Obok opisanej kategorii półsurowca, tj. wiórów, ale i odłupków uzyskiwanych w ramach koncepcji rdzenia wiórowego opartej na technice pośrednika (ryc. 3, 6: 7), w inwentarzu obecne są też pojedyncze produkty związane z realizacją koncepcji odłupkowej. Świadectwem jej stosowania są drobne, silnie wyzyskane rdzenie, tzw. globuleux (Kozłowski, 1970, s. 79; Kaczanowska, 1971, s. 14; Caspar i in., 1989, s. 178) oraz formy łuszczniowe. Należy jednak podkreślić, że do produkcji narzędzi wykorzystywano głównie wióry stanowiące podstawowy typ półsurowca, charakterystyczny dla wszystkich kategorii form retuszowanych. Efektem takiego modelu jest wyraźna standaryzacja 

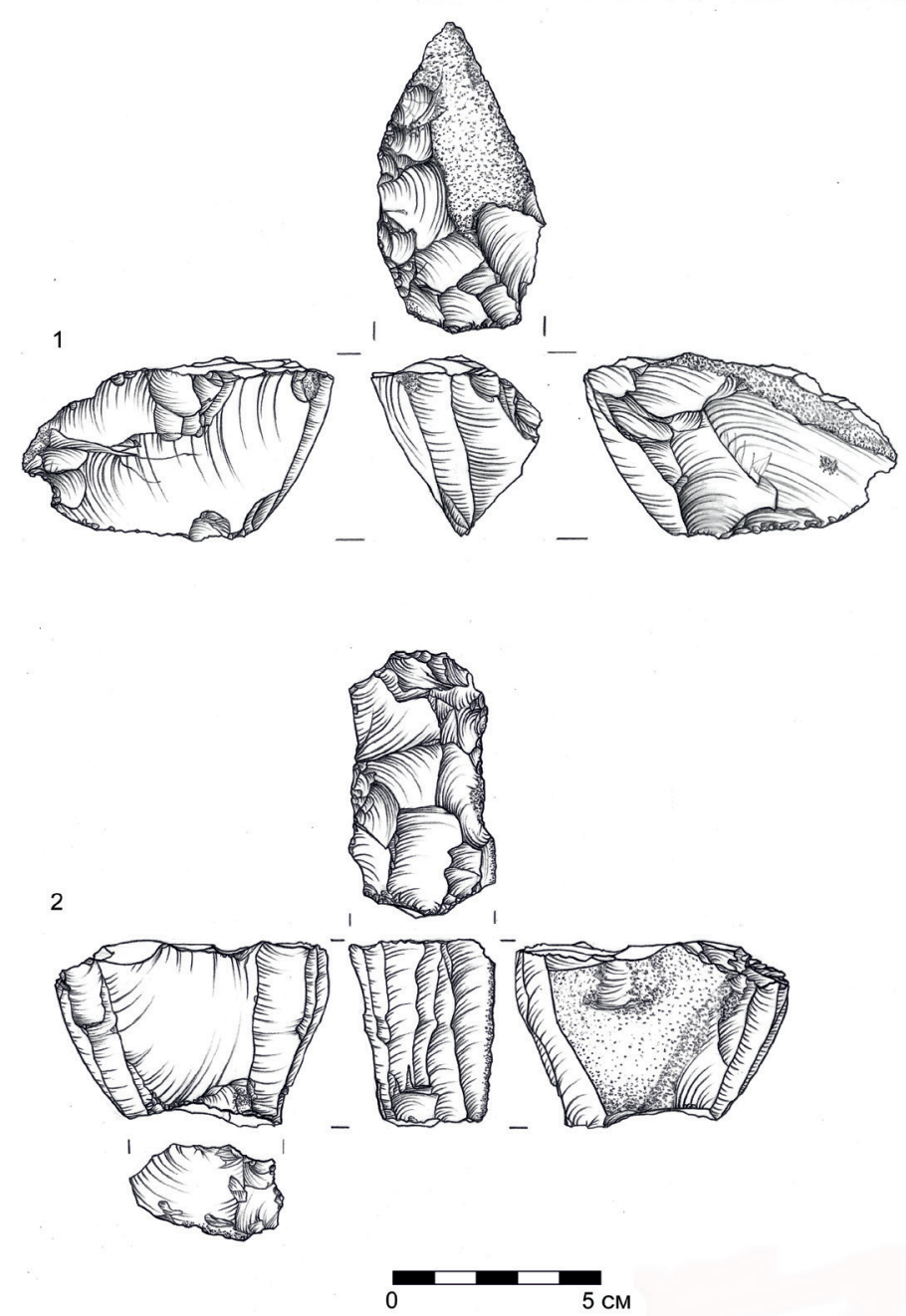

Ryc. 3. Przykłady rdzeni wiórowych eksploatowanych techniką pośrednika (rys. A. Pałasz)

Fig. 3. Examples of blade cores with indirect debitage technique (drawing by A. Pałasz)

parametrów morfologicznych narzędzi. Przejawia się ona nie tylko w proporcjach i wyjątkowej regularności wytworów, ale także w sposobie wykonywania retuszy (np. słabo zakolone lub wręcz liniowe drapiska) oraz stosowanych modyfikacji np. zabieg sekcjonowania (Domańska, 1989, s. 353). Przytoczone elementy charakterystyki stylistycznej oraz technologicznej materiałów krzemiennych z Podlesia 6 są typowe dla krzemieniarstwa KCWR i znajdują ścisłe analogie w licznych inwentarzach tej jednostki, w zasadzie na całym obszarze jej występowania. 


\section{Charakterystyka typologiczna}

Dominującą kategorią w badanym zbiorze są produkty debitażu, stanowiące ponad $71,1 \%$. Kolejne miejsce zajmują narzędzia, w tym zarówno formy retuszowane, jak i nieretuszowane, ale ze śladami modyfikacji użytkowych, łącznie $22,2 \%$, następnie destrukty, $\mathrm{tj}$. okruchy termogeniczne, kriogeniczne oraz przemysłowe, łącznie 6,6\%, a także manuporty, tj. naturalne konkrecje surowca (ok. 1,2\%) (ryc. 4). Najliczniejszą grupę produktów debitażu tworzą odłupki (818 szt.) będące prawdopodobnie pozostałością obróbki przydomowej (ryc. 4). Morfometrycznie są to przede wszystkim małe i średniej wielkości $(3-5 \mathrm{~cm})$ okazy o przygotowanych jednym odbiciem lub fasetowanych piętkach. W skromnej (21 szt.) grupie odłupków technicznych występują przede wszystkim świeżaki oraz odłupki korygujące, odłupnie np. znoszące zawiasy. Stwierdzono również stosunkowo niewielką liczbę odłupków korowych (161 szt.). Podobnie jak w przypadku ogólnej struktury inwentarza, tak i wśród odłupków najliczniej reprezentowane są formy z krzemienia jurajskiego. Co ciekawe, wyjątek stanowi podgrupa odłupków korowych, w której dominują okazy wykonane z krzemienia święciechowskiego. Jest to ważna obserwacja, wskazująca na nieco inne modele aprowizacji w te surowce, gdzie pierwszy docierał na stanowisko w postaci częściowo już okorowanych brył (obłupni, a może nawet rdzeni), natomiast drugi w formie surowych konkrecji. Drugą grupę produktów debitażu są wióry i ich fragmenty (355 szt.), do których należy zaliczyć również wiórowe narzędzia retuszowane (ryc. 4). Przeważają formy płaskie, dość regularne, o fasetowanych piętkach. Odnotowano tylko 45 wiórów podkorowych oraz 35 tzw. form technicznych, głownie podtępce oraz wióry korygujące odłupnię, co ciekawe

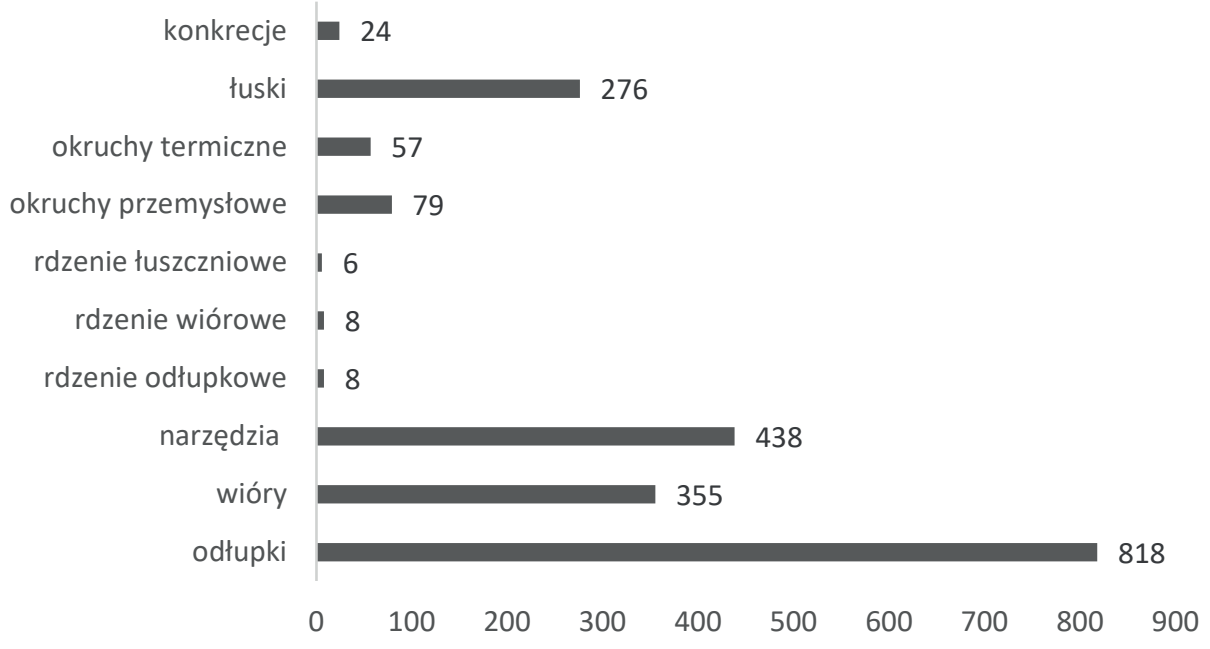

Ryc. 4. Frekwencja głównych kategorii typologicznych (rys. M. Przeździecki)

Fig. 4. Frequency of the main typological categories (drawing by M. Przeździecki) 
z wyjątkiem zatępców. Debitaż uzupełniają grupy łusek (276 szt.) oraz okruchów przemysłowych (79 szt.) (ryc. 4). Niewielka, mimo przyjętych standardów wykopaliskowych, liczba łusek wskazuje, że obróbka krzemienia bezpośrednio na stanowisku była stosowana w ograniczonym stopniu i miała charakter przydomowy. Potwierdza to również stosunkowo skromna liczba 22 rdzeni -8 wiórowych (ryc. 3, 6: 7), 8 odłupkowych i 6 łuszczniowych.

Analizując kategorię narzędzi (ryc. 5), należy zwrócić uwagę, przede wszystkim na wspominaną już wcześniej standaryzację parametrów morfometrycznych. Najliczniejszą, ale zarazem najbardziej enigmatyczną grupę definiują tzw. narzędzia funkcjonalne, są to wyłącznie bardzo regularne formy wiórowe, zazwyczaj sekcjonowane, wykonywane z medialnych partii wiórów, charakteryzujące się prostym profilem o stałej grubości oraz równoległym układem krawędzi bocznych (ryc. 6: 1, 2, 4, 7: 3-6). Do najistotniejszych cech decydujących o zaliczeniu tych form do grupy narzędzi decyduje obecność mniej lub bardziej wyraźnych wyszczerbień bądź bardzo drobne negatywy wzdłuż krawędzi, niekiedy w towarzystwie widocznych makroskopowo wyświeceń (por. Małecka-Kukawka, 1999). W zestawie form retuszowanych najliczniejsze są drapacze definiowane przez 143 okazy (ryc. 7: 7-13), drugą pozycję zajmują wiórowce lub wióry retuszowane, łącznie 52 szt. (ryc. 6:3, 5, 6:14), następnie półtylczaki (32 szt.) (ryc. 6:1). Frekwencja pozostałych typów narzędzi nie przekracza kilkunastu okazów, przy czym w grupie tej znalazły się takie formy, jak przekłuwacze (ryc. 7: 1,2), skrobacze, tylczaki, zbrojniki trapezowate oraz thuczki krzemienne. Zarejestrowano też pojedyncze zgrzebło (ryc. 6: 6). Ponadto w zbiorze wystąpiło siedem zabytków, które w prawdzie posiadały ślady retuszu, ale ze względu na wysoki stopień fragmentacji nie było możliwe dokładne określenie ich typu.

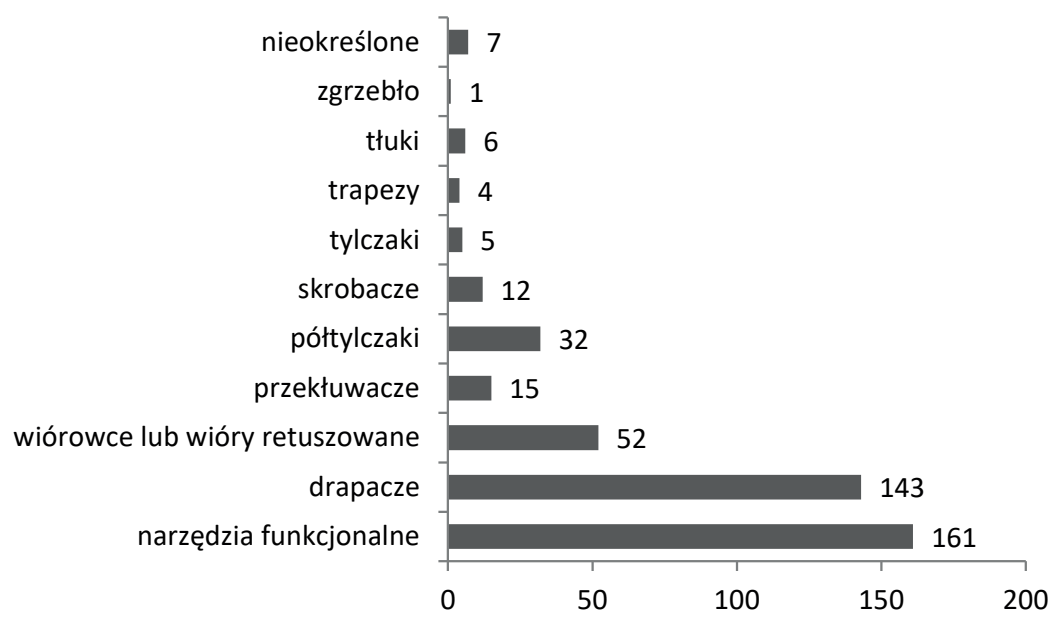

Ryc. 5. Frekwencja poszczególnych typów narzędzi krzemiennych (rys. M. Przeździecki)

Fig. 5. Frequency of flint tools types (drawing by M. Przeździecki) 

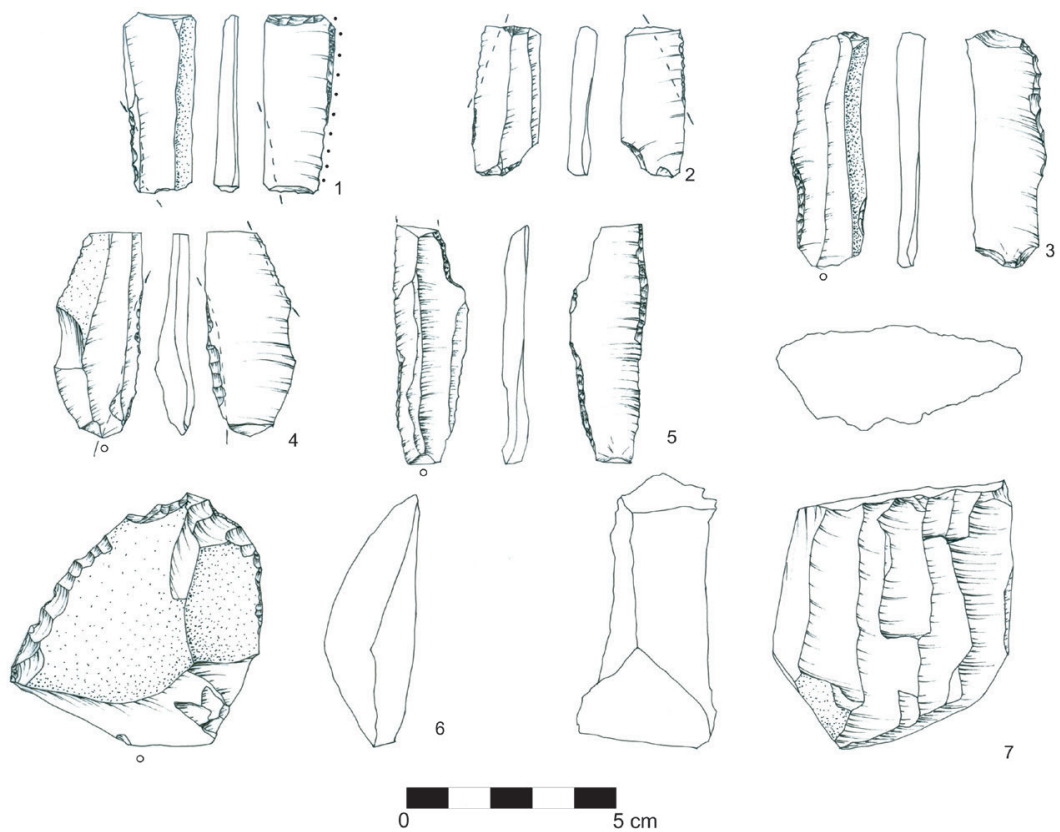

Ryc. 6. Przykłady zabytków krzemiennych (rys. A. Czubińska)

Fig. 6. Examples of flint artefacts (drawing by A. Czubińska)
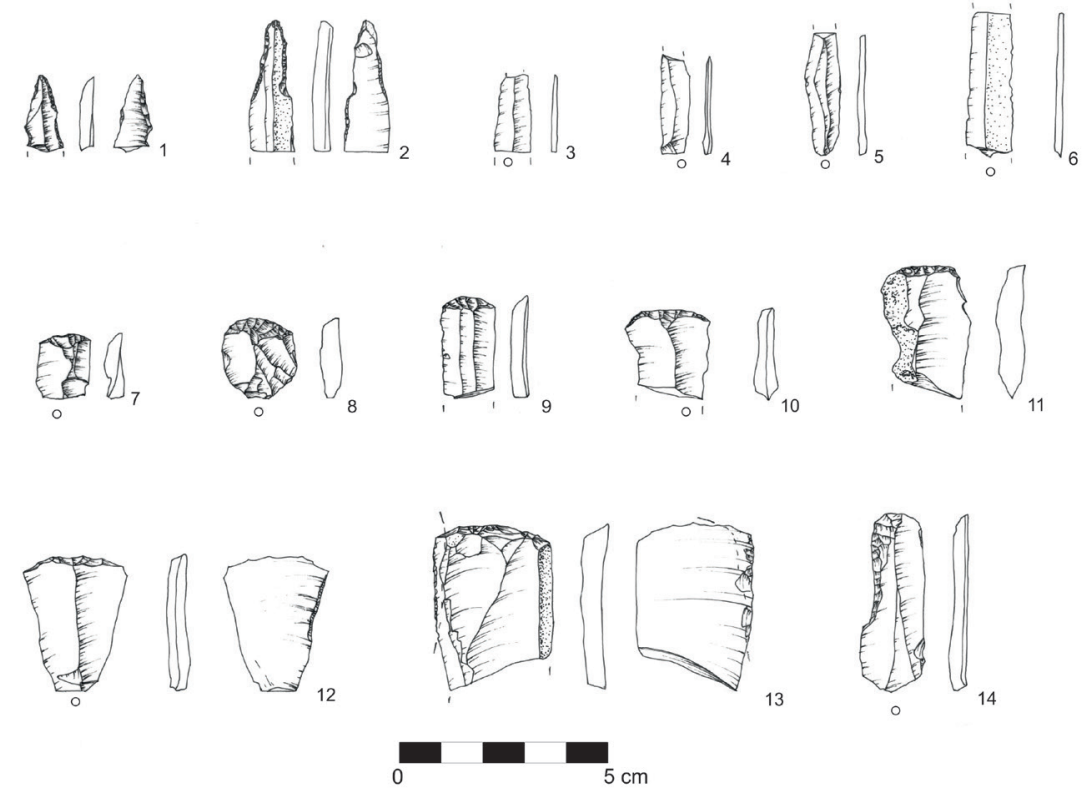

Ryc. 7. Przykłady zabytków krzemiennych (rys. A. Czubińska)

Fig. 7. Frequency of particular flint types (drawing by A. Czubińska) 


\section{DYSKUSJA}

Studia nad krzemieniarstwem neolitycznym, w tym społeczności związanych z KCWR, sięgają lat 60 . XX w. Za symboliczny początek zainteresowania tym tematem uznaje się zorganizowaną w 1969 roku konferencję w Nowej Hucie o KCWR (Kozłowski, 1970a) oraz rok później poświęconą już stricte krzemieniarstwu neolitycznemu (Kozłowski, 1971; Balcer, 1983, s. 20). Zarysowano wtedy ogólną problematykę studiów, a także opublikowano pierwsze wnioski w zakresie metod badań tego typu zespołów z terenów Polski (Kozłowski, 1970b; Lech, 1979).

Wzmożone zainteresowanie stanowiskami z wczesnych faz neolitu poskutkowało intensywnym rozwojem w zakresie opisu oraz sposobów analizy omawianej kategorii inwentarzy. W pierwszej kolejności doprowadziło to do powstania list dynamicznej klasyfikacji typologicznej dla materiałów z tego okresu (Dzieduszycka-Machnikowa, Lech, 1976; Schild i in., 1985; por. Ehlert, 2012). Następnie, aby wymienić najważniejsze: opracowaniami materiałów krzemiennych w kontekście regionalnym (Kaczanowska, 1987; Małecka-Kukawka, 1992; Kabaciński, 2010; Ehlert, 2014), badaniami nad gospodarką surowcową (Lech, 1981, 1982/1983, 1983, 2003), analizami funkcjonalnymi (Małecka-Kukawka, 2001, 2012) oraz w ostatnich latach zagadnieniami technologicznymi (Wąs, 2011; Ehlert, 2014). Niemniej większość postulatów sformułowanych u schyłku lat 80 . XX w., przy okazji ważnej metodologicznie dyskusji między J. Lechem $(1988,1989)$ a B. Balcerem (1990) jest nadal aktualna i daje teoretyczne podstawy do dalszych analiz. Zawsze badacze zwracali dużą uwagę m.in. na homogeniczność materiałów krzemiennych KCWR pod względem morfologiczno-typologicznym, kładąc nacisk na zróżnicowanie w kwestii surowcowej, świadczące o kontaktach międzygrupowych (Lech, 1997, s. 260; 2003, s. 24-27; KeglerGrajewski, Zimmermann, 2003; Mateiciucová, 2008)

Autorzy piszący o wczesnoneolitycznym osadnictwie często podkreślają rolę, jaką odgrywał dobrej jakości krzemień o charakterystycznych właściwościach (barwa, tekstura, łupliwość itp.), który posiadał prawdopodobnie istotne znaczenie spajające społeczność (np. Małecka-Kukawka, 1994; Kruk, Milisauskas, 1999, s. 57; Lech, 2003).

W bogatym zbiorze artefaktów krzemiennych z Podlesia dominuje krzemień jurajski. Należy jednak zaznaczyć, że współwystępują z nim w zasadzie wszystkie główne surowce krzemionkowe znane z terenów ziem polskich. Docierały one z trzech kierunków - od zachodu (surowce jurajskie), od wschodu (krzemienie czekoladowy i turońskie) oraz z południa (obsydian). Biorąc pod uwagę, że najbliższe wychodnie surowców od stanowiska w Podlesiu zlokalizowane są w odległości ponad $50 \mathrm{~km}$, zasadne jest uznawanie ich za surowce importowane.

Stanowisko $6 \mathrm{w}$ Podlesiu wymyka się jednak standardowemu podziałowi na osady producentów i użytkowników surowców krzemiennych w społecznościach KCWR. Dominacja odmian importowanych, szczególnie krzemienia jurajskiego podkrakowskiego, który docierał do osady z odległości ponad 100 km, wskazywałaby na strukturę inwentarza typową raczej dla osady użytkowników. Tego rodzaju punkty, 
zlokalizowane zazwyczaj w dużej odległości od złóż krzemieni kopalnych, bazowały na importowanym surowcu, który docierał do nich w postaci przygotowanych rdzeni bądź gotowych wiórów (Lech, 1997). Strukturę takiego inwentarza określa stosunek rdzeni i odłupków do wiórów i narzędzi w przedziale ok. 45\% do 55\% (Lech, 2003, s. 22; Szubski, 2015). W przypadku osady KCWR w Podlesiu stosunek ten wynosi $52 \%$ do $48 \%$, czyli niemal po równo. Znikoma liczba rdzeni (zaledwie 22 okazy w zbiorze liczącym łącznie 2069 wytworów) wskazuje raczej na dopływ gotowych, przygotowanych obłupni o zredukowanej masie. Wysoki procent odłupków (zwiększony znacznie, gdyby dodać łuski oraz okruchy techniczne) wskazuje jednak na intensywną obróbkę przydomową, a stosunkowo duże wytwory z dobrych surowców krzemionkowych oraz niewielka liczba destruktów, form będących świadectwem błędów technicznych (tzw. odłupków zawiasowych lub przeniesionych), a także znikomy udział produktów eksploatacji łuszczniowej wykazują na zaawansowane umiejętności lokalnych krzemieniarzy.

Duża liczba zabytków krzemiennych o bardzo zróżnicowanym profilu surowcowym bez wątpienia jest wynikiem specyficznej lokalizacji stanowiska. Osada w Podlesiu, położona między dokładnie trzema prowincjami surowcowymi, mogła być istotnym punktem na mapie ówczesnych szlaków komunikacyjnych, na co pośrednio wskazuje stosunkowo duża liczba obsydianów. Osada leżała niejako na granicy światów, czyli zachodniej i wschodniej ekumeny KCWR (ryc. 8). Wysoki udział surowców importowanych (niemal 90\% zbioru) z odległości ponad $50 \mathrm{~km}$ jest szczególnie zaskakujący ze względu na relatywnie niewielkie rozmiary osady oraz jej położenie poza strefą lessów (ryc. 1). Niemniej duża liczba artefaktów krzemiennych wskazuje na jej szczególne miejsce w sieci osadniczej KCWR.

Podkreślając wyjątkowy charakter stanowiska, należy także zwrócić uwagę na homogeniczność materiałów związanych wyłącznie z KCWR, choć reprezentujących różne fazy. Dotychczas tego typu inwentarze (pozbawione obcych domieszek) spotykane były tylko w kontekście badań osad z obszaru Niżu (por. Małecka-Kukawka, 2001, s. 163). Pozwala to na przeprowadzenie unikatowych studiów stanowiska tylko pod kątem osadnictwa wczesnoneolitycznego. Jest to szczególnie ważne w przypadku obserwacji chronologii wewnętrznej w obrębie jednego kompleksu kulturowego. Przeprowadzone obserwacje relacji przestrzennych na stanowisku w Podlesiu w kilku przypadkach stwarzają podstawy do łączenia ceramiki z różnych faz z konkretnymi grupami wytworów krzemiennych. Dotyczy to:

a. obiektów $\mathrm{nr} 1 \mathrm{i} \mathrm{nr} 2$, gdzie zabytkom krzemiennym towarzyszyła ceramika z fazy nutowej, żeliezowskiej, a także fragmenty naczyń z kręgu wschodniolinearnego oraz kolekcja przedmiotów obsydianowych;

b. obiektu $\mathrm{nr} 8$, gdzie oprócz zabytków krzemiennych wystąpiła wyłącznie ceramika z fazy nutowej.

W pozostałych obiektach nie zarejestrowano materiałów diagnostycznych w stopniu umożliwiającym precyzyjne określenie ich chronologii.

Obiekt 8, o wyraźnie starszej chronologii, jest szczególnie dobrym przyczynkiem do dyskusji o początkach eksploatacji surowców krzemiennych przez społeczności 


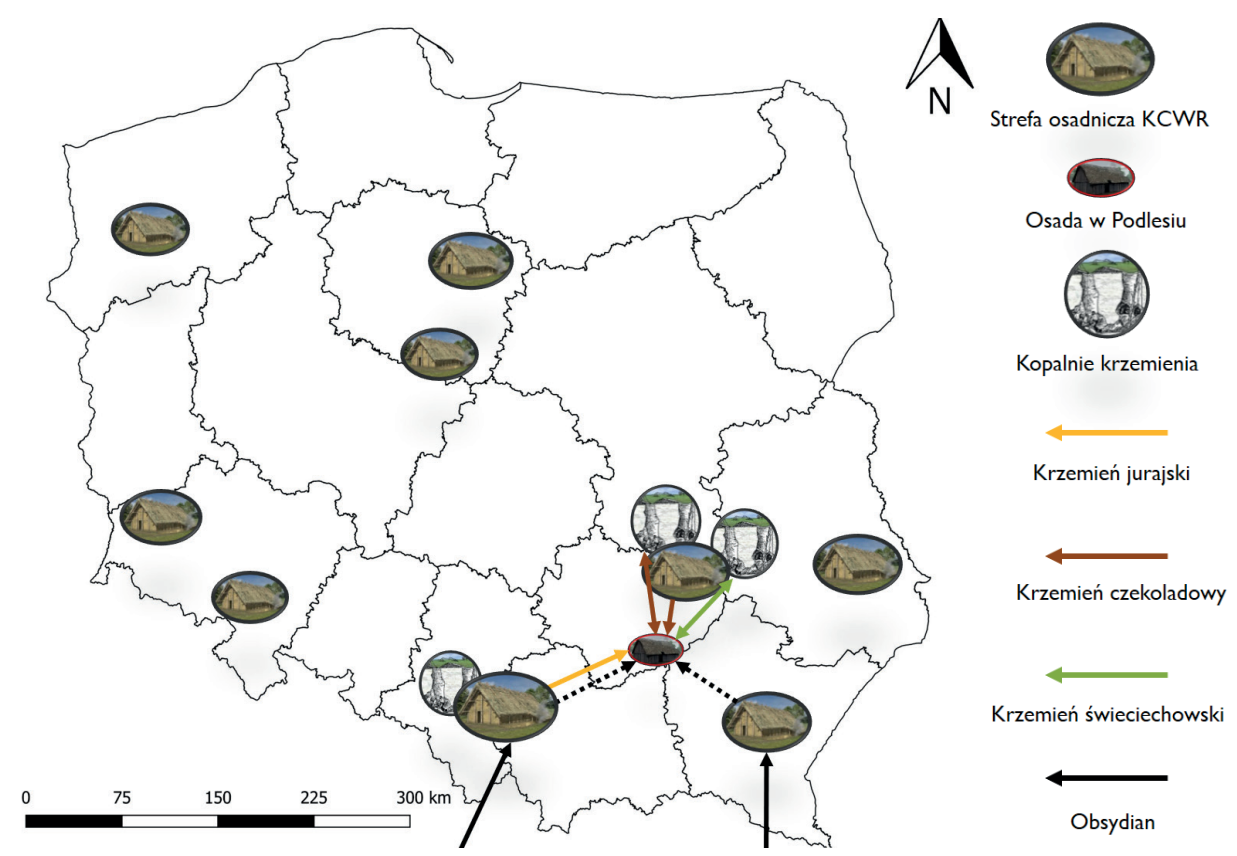

Ryc. 8. Mapa hipotetycznych źródeł dopływu surowców krzemiennych do osady w Podlesiu (wg J. Lech 2003) (rys. M. Szubski)

Fig. 8. Hypothetical map of sources of flints income to settlement in Podlesie (after J. Lech 2003) (drawing by M. Szubski)

KCWR. Postawiona hipoteza, że we wczesnym okresie osadnictwa społeczności wstęgowej, zasiedlając obszary południowej Polski, eksploatowały na dużą skalę krzemień jurajski, zdaje się w tym przypadku adekwatna. Wraz z ekspansją terytorialną wczesnoneolityczne społeczności adaptowały inne, łatwo dostępne źródła krzemieni z wschodniego obrzeżenia Gór Świętokrzyskich (Lech, 1988, s. 318; odmienne zdanie por. Małecka-Kukawka, 2011, s. 159-164). Obraz taki widzimy na badanym stanowisku, gdzie materiały fazy klasycznej KCWR występują prawie wyłącznie z importowanym krzemieniem jurajskim ( $95 \%$ zbioru krzemienie z obiektu 8 stanowi surowiec jurajski). Wraz z rozwojem osadnictwa na stanowisku 6, szczególnie obserwowalnymi wpływami wschodniolinearnymi, pojawiają się na dużą skalę krzemień czekoladowy, świeciechowski oraz obsydian.

\section{PODSUMOWANIE}

Osada w Podlesiu jest z wielu powodów stanowiskiem wyjątkowym. Świadczy o tym przede wszystkim jego położenie: na granicy dwóch krain geograficznych, dwóch uwarunkowań geologicznych, dwóch ekumen osadniczych KCWR oraz 
dwóch prowincji surowców krzemiennych. Bez wątpienia szersze rozpoznanie wykopaliskowe stanowiska jest niezbędne, aby zrozumieć zachodzące na nim procesy oraz potwierdzających wyjątkową rolę, jaką osada pełniła w ówczesnym świecie.

\section{BIBLIOGRAFIA}

Balcer, B.

1983 Wytwórczość narzędzi krzemiennych w neolicie ziem polskich. Wrocław - Warszawa Kraków - Gdańsk - Łódź: Ossolineum.

1990 Do dyskusji na temat krzemieniarstwa neolitycznego i neolityzacji ziem polskich. Archeologia Polski, 35(2), 311-329.

Budziszowski, J.

2008 Stan badań nad występowaniem i pradziejową eksploatacją krzemieni czekoladowych.

W: W. Borkowski, J. Libera, B. Sałacińska, S. Sałaciński (red.), Krzemień czekoladowy w pradziejach. Materialy z konferencji w Orońsku, 08-10.10.2003 (s. 33-106). Warszawa - Lublin: Państwowe Muzeum Archeologiczne, Stowarzyszenie Naukowe Archeologów Polskich Oddział w Warszawie, Instytut Archeologii Uniwersytetu Marii Curie-Skłodowskiej w Lublinie.

Bujakowski, W., Kmicik, M.

2005 Iłża-Chwałowski Trakt, st. 21, gm. loco, woj. radomskie, AZP 79-69. Informator Archeologiczny. Badania 1996, 31, 38-39.

Caspar, J.-P., Kaczanowska, M., Kozłowski, J. K.

1989 Chipped stone industries of linear band pottery (LBP): Techniques, morphology and function of the implements in Belgian and Polish assemblages. Helinium, 29, 157-205.

Domańska, L.

1989 Some remarks on the differentiation of lithic assembladges of linear band pottery culture from the Kujawy region. W: J. K. Kozłowski, S. K. Kozłowski (red.), Chipped stone industries of the Early Farming Cultures in Europe, Archaeologia Interregionalis, t. 9 (s. 351-359). Warsaw - Cracow: Warsaw University, Jagiellonian University Cracow.

Dzieduszycka-Machnikowa, A., Lech, J.

1976 Neolityczne zespoty pracowniane z kopalni krzemienia w Saspowie (Polskie Badania Archeologiczne, t. 19). Wrocław - Warszawa - Kraków - Gdańsk: Ossolineum.

Ehlert, M.

2012 Flint versus lists: Lithic Industries of Early Farming Communities in Central Europe and Classification Tools. W: J. Koláŕ, F. Trampota (red.), Theoretical and Methodological Considerations in Central European Neolithic Archaeology. Proceedings of the 'Theory and Method in Archaeology of the Neolithic ( $7^{\text {th }}-3^{\text {rd }}$ millennium BC)' conference held in Mikulov, Czech Republic, $26^{\text {th }}-8^{\text {th }}$ of October 2010. (s. 65-76) (BAR International. Series 235). Oxford: Archaeopress.

2014 Krzemieniarstwo pierwszych rolników na Śląsku. Wrocław: Wydawnictwo Uniwersyteckie.

Hadamik, C.

2005 Bukówka-Zapniów, st. 1, gm. Pawłów, woj. świętokrzyskie, AZP 83-68/35. Informator

Gromnicki, J. Archeologiczny. Badania 1996, 31, 31-32.

1965 Sprawozdanie z badań cmentarzyska kultury grobów kloszowych w Zagości-Parcelacji, powiat Pińczów w latach 1962-1963. Sprawozdania Archeologiczne, 17, 171-172. 
Kabaciński, J.

2010 Przemiany wytwórczości krzemieniarskiej społeczności kultur wstęowych strefy wielkodolinnej Niżu Polskiego. Poznań: Wydawnictwo Instytutu Archeologii i Etnologii PAN.

Kaczanowska, M.

1971 Krzemienne materiały kultur neolitycznych pochodzenia południowego z terenu Nowej Huty. W: J. K. Kozłowski (red.), Z badań nad kultura ceramiki wstęgowej rytej. Referaty $i$ komunikaty przedstawione na sympozjum w Nowej Hucie dn. 10, 11 maja 1971 r. (s. 10-24). Kraków: Polskie Towarzystwo Archeologiczne. Oddział w Nowej Hucie.

1985 Rohstoffe, Technik und Typologie der Neolithischen feuersteinindustrien im nordteil des flussgebietes der mitteldonau. Warszawa: Państwowe Wydawnictwo Naukowe.

1989 Die Feuersteinindustrie der ältesten Landgemeinschaften in Südpolen. W: J. K. Kozłowski, S. K. Kozłowski (red.), Chipped stone industries of the Early Farming Cultures in Europe (Archaeologia Interregionalis, t. 9) (s. 351-359). Warsaw - Cracow: Warsaw University, Jagiellonian University Cracow.

Kaczanowska, M., Kozłowski, J. K.

1976 Studia nad surowcami krzemiennymi południowo-wschodniej części Wyżyny Krakowsko-Częstochowskiej. Acta Archaeologica Carpathica, 26, 201-215.

Kegler-Grajewski, N., Zimmermann, A.

2003 Exchange systems of stone artefacts in the european Neolithic. W: L. Burnez-Lanotte (red.), Production and management of lithic materials in the European Linearbandkeramik, (BAR International, Series 1200) (s. 31-35). Oxford: Archaeopress.

Kondracki, J.

2002 Geografia regionalna Polski. Warszawa: Wydawnictwo Naukowe PWN.

Kozłowski J. K. (red.)

1970a Z Zadań nad kultura ceramiki wstęgowej rytej. Referaty i komunikaty przedstawione na sympozjum w Nowej Hucie dn. 10, 11 maja 1971 r. Kraków: Polskie Towarzystwo Archeologiczne Oddział w Nowej Hucie.

Kozłowski, J. K.

1970b Z badań nad wytwórczością krzemieniarską w kulturze ceramiki wstęgowej rytej. W: J. K. Kozłowski (red.), Z badań nad kultura ceramiki wstęgowej rytej. Referaty i komunikaty przedstawione na sympozjum w Nowej Hucie dn. 10, 11 maja 1971 r. (s. 73-94). Kraków: Polskie Towarzystwo Archeologiczne Oddział w Nowej Hucie.

1971 Uwagi o znaczeniu i metodach badań nad neolitycznymi inwentarzami krzemiennymi. W: J. K. Kozłowski (red.), Z badań nad kultura ceramiki wstęgowej rytej. Referaty i komunikaty przedstawione na sympozjum w Nowej Hucie dn. 10, 11 maja 1971 r. (s. 139-149). Kraków: Polskie Towarzystwo Archeologiczne Oddział w Nowej Hucie.

Krauss, J.

1970 Wielokulturowe stanowisko w Kowali, pow. Proszowice. Materiaty Archeologiczne, 9, 157-174.

Kruk, J.

1969 Badania poszukiwawcze i weryfikacyjne w dorzeczu Dłubni. Sprawozdania Archeologiczne, 21, 356-357.

Kruk, J., Milisauskas, S.

1999 Rozkwit i upadek społeczeństw rolniczych neolitu. Kraków: Instytut Archeologii i Etnologii PAN.

Kulczycka-Leciejewiczowa, A. (red.)

2008 Samborzec. Studium przemian kultury ceramiki wstęgowej rytej. Wrocław: Instytut Archeologii i Etnologii PAN.

Lech, J.

1979 Krzemieniarstwo w kulturze społeczności ceramiki wstęgowej rytej w Polsce. Próba zarysu. W: W. Wojciechowski (red.), Początki neolityzacji w Polsce poludniowo-zachodniej 
1980 stycznych

1980 Geologia krzemienia jurajskiego-podkrakowskiego na tle innych skał krzemionkowych. Wprowadzenie do badań z perspektywy archeologa. Acta Archaeologica Carpathica, 20, $163-228$.

1981 Górnictwo krzemienia społeczności wczesnorolniczych na Wyżynie Krakowskiej. Koniec VI tysiaclecia - 1 połowa IV tysiaclecia p.n.e. Wrocław - Warszawa - Kraków - Gdańsk Łódź: Zakład Narodowy im. Ossolińskich.

1982/1983 Flint work of the early farmers. Oriduction trends in central European chipping industries from 4500-1200 BC. An outline. Acta Archaeologica Carpathica, 22, 5-63.

1983 Górnictwo surowców krzemiennych w kulturze społeczności wczesnorolniczych na terytorium Polski. W: J. K. Kozłowski, S. K. Kozłowski (red.), Człowiek i środowisko w pradziejach (s. 114-126). Warszawa: Państwowe Wydawnictwo Naukowe.

1988 O rewolucji neolitycznej i krzemieniarstwie, cz. 1: Wokół metody. Archeologia Polski, 33(2), 273-345.

1989 O rewolucji neolitycznej i krzemieniarstwie, cz. 2: Wokół neolityzacji dorzecza Wisły i Odry. Archeologia Polski, 34(1), 55-125.

1997 Remarks on prehistoric flint mining and flint supply in European archaeology. W: A. Ramos-Millán, M. A. Bustillo (red.), Siliceous rocks and culture (Monográfica Arte y Arqueología, 42) (s. 611-637). Granada: Universidad de Granada.

2003 Mining and siliceous rock supply to the Danubian early farming communities (LBK) in eastern central Europe: A second approach. W: L. Burnez-Lanotte (red.), Production and management of lithic materials in the European Linearbandkeramik (BAR International, Series 1200) (s. 19-30). Oxford: Archaeopress.

2008 Materiały krzemienne społeczności kultury ceramiki wstęgowej rytej z Samborca, pow. Sandomierz. W: A. Kulczycka-Leciejewiczowa (red.), Samborzec. Studium przemian kultury ceramiki wstegowej rytej (s. 151-202). Wrocław: Instytut Archeologii i Etnologii PAN.

Libera, J., Zakościelna, A.

2002 Złoża krzemieni turońskich na obszarze przełomowego odcinka Wisły. W: B. Matraszek, S. Sałaciński (red.), Krzemień świeciechowski w pradziejach. Materiaty z konferencji w Ryni 22-24. 05. 2000 (Studia nad Gospodarką Surowcami Krzemiennymi w Pradziejach, 4) (s. 93-109). Warszawa: Państwowe Muzeum Archeologiczne, Stowarzyszenie Naukowe Archeologów Polskich, Instytut Archeologii i Etnologii PAN.

Małecka-Kukawka, J.

1992 Krzemieniarstwo społeczności wczesnorolniczych ziemi chelmińskiej (2 połowa VI-IV tysiaclecie p.n.e.). Toruń: Wydawnictwo Uniwersytetu Mikołaja Kopernika.

1994 „Gospodarka” surowcami krzemiennymi wśród społeczności wczesnorolniczych ziemi chełmińskiej z perspektywy teorii wymiany społecznej. W: L. Czerniak (red.), Neolit i początki epoki brązu na ziemi chetmińskiej (s. 37-50). Grudziądz - Toruń: Muzeum w Grudziądzu, Instytut Archeologii i Etnologii UMK.

1999 Sierpy, sierpaki, sierpce... - analiza funkcjonalna wczesnorolniczych wkładek narzędzi żniwnych z ziemi chełmińskiej. W: S. Kukawka (red.), Szkice prahistoryczne, Źródła metody-interpretacje (s. 139-158). Toruń: Wydawnictwo Naukowe Uniwersytetu Mikołaja Kopernika.

2001 Między forma a funkcją. Traseologia neolitycznych zabytków krzemiennych ziemi chetmińskiej. Toruń: Wydawnictwo Naukowe Uniwersytetu Mikołaja Kopernika.

2017 Traseologia $w$ studiach nad pradziejowym krzemieniarstwem. Przyklady z osad $i$ kopaln krzemienia w dorzeczach Wisty i Odry. Toruń: Wydawnictwo Naukowe Uniwersytetu Mikołaja Kopernika. 
Mateiciucová, I.

2008 Talking stones: the chipped stone industry in Lower Austria and Moravia and the beginnings of the Neolithic in Central Europe (LBK), 5700-4900 BC. Brno: Masarykova Univerzita.

Matyaszewski, M.

2017 Sprawozdanie z ratowniczych badań archeologicznych stanowiska $n r 33$ w Wólce Wojnowskiej, gm. Ćmielów, pow. ostrowiecki, woj. świętokrzyskie, wykonywanych w 2017

Schild, R. roku w zwiqzku z budowa obwodnicy Ćmielowa (Unpublished typescript). Sandomierz.

1971 Lokalizacja prahistorycznych punktów eksploatacji krzemienia czekoladowego na północno-wschodnim obrzeżeniu Gór Świętokrzyskich. Folia Quaternaria, 39, 1-61.

Schild, R., Królik, H., Marczak, M.

1985 Kopalnia krzemienia czekoladowego w Tomaszowie. Wrocław - Warszawa - Kraków Gdańsk - Łódź: Zakład Narodowy Imienia Ossolińskich.

Szeliga, M., Przeździecki, M., Grabarek, A.

2019 Podlesie, Site 6 - the First Obsidian Inventory of the Linear Pottery Culture Communities from the Połaniec Basin. Archaeologia Polona, 57, 197-211.

Szeliga, M., Zakościelna, A.,

2009 Wstępne sprawozdanie z ratowniczych badań wykopaliskowych na wielokulturowym stanowisku 6 w Tominach, pow. opatowski w 2006 roku. Archeologia Polski Środkowowschodniej, 9, 9-23.

Szubski, M.

2015 Krzemień lokalny w osadzie użytkowników? Gospodarka surowcowa w kulturze ceramiki wstęgowej rytej na stanowisku w Bodzowie, woj. Lubuskie. Acta Universitatis Nicolai Copernici. Archeologia, 34, 237-348.

Wąs, M.

2011 Janisławickie” i „wstęgowe” koncepcje rdzeniowania wiórowego. Próba konfrontacji technologicznej. Acta Universitatis Lodziensis. Folia Archaeologica, 28, 5-21.

\section{BETWEEN EAST AND WEST. FLINT ASSEMBBLAGE OF THE LINEAR POTTERY CULTURE SOCIETIES FROM SITE 6 IN PODLESIE, ŚWIĘTOKRZYSKIE VOIVODESHIP}

\section{Sum mary}

The aim of the paper is to present the preliminary results of the analysis of the assemblage of flint artefacts from the settlement of the Linear Pottery culture (later abbreviated as LBK) at the site no. 6 in Podlesie, Staszowski commune, Świętokrzyskie voivodeship. The main attention has been put on one aspect that is particularly interesting from the perspective of the conducted research characteristics of the raw material sources. Podlesie is a small village located in the central part of the Połaniecka Basin, defining one of the mesoregions of the Małopolska Upland. Based on the results of fieldwalk, drills, as well as geophysical surveys, the size of the LBK settlement should be estimated at approx. 2 ha.

Since 2014, excavations have been carried out at this site, managed by Artur Grabarek from the Institute of Archeology at the University of Warsaw. During five research seasons, an area of 3.8 ares was identified, registering at the same time 10 objects. From their fills and from the cultural layer, a total of approx. 14.5 thousand artefacts were acquired. Within the flint assemblage we can 
distinguish two main classes of lithical artefacts: an internally cohesive collection of 104 obsidian products and a collection of 2069 artefacts made of at least five different types of flint. In the group of siliceous rocks, the most numerous is the Jurassic flint from Cracow area $-53 \%$. Second place in the inventory is occupied by the Światchowski flint, which share reaches the level of $19 \%$. Only slightly smaller are amounts of chocolate flint $-15 \%$ (fig. 6). Different situation is in the case of erratic flints, i.e., the Baltic flint, which was defined by $5 \%$ of products and banded flint represented by only two artefacts. The analyzed collection also included, approximately $6 \%$, of thermally transformed (burnt) artefacts, which were impossible to identify as raw material type.

Site 6 in Podlesie defies the standard division into the settlement of producers and users of flint raw materials in LBK communities. The dominance of imported siliceous rocks - especially the Jurassic flint, which reached the settlement from a distance of over $100 \mathrm{~km}$ - would indicate the structure of inventory typical of the settlement of users. Such a structure has a defined ratio of cores and flakes to blades and tools in the range of about 45\%: 55\% (Lech, 2003, p. 22; Szubski, 2015). The ratio of the LBK in Podlesie are 52\%: 48\% - almost equally. The usual number of cores (only 22 specimens in a collection of 2069 products), indicating rather the inflow of finished, prepared cores with reduced mass. High percentage of flakes (increased considerably if it were to add chips and technical chunks) indicates, however, intensive household processing, and relatively large products from good raw materials show the advanced skill of local flintknappers.

The settlement in Podlesie is an exceptional site for many reasons. This is evidenced primarily by its location: on the border of two geographical regions, two geological conditions, two settlement eccentrics of the LBK and two provinces of lithic raw materials. Undoubtedly, a wider exploration of the position is necessary to understand the processes taking place there and to confirm the unique role that the settlement played in the contemporary world. 